\title{
Synthesis and characterization of carboxymethyl chitosan hydrogel: Application as site specific delivery for lercanidipine hydrochloride
}

\author{
SUBHASH S VAGHANI*, MADHABHAI M PATEL ${ }^{1}$, C S SATISH $^{2}$, KANDARP M PATEL $^{3}$ and \\ N P JIVANI ${ }^{4}$ \\ Jodhpur National University, Jodhpur 342 003, India \\ ${ }^{1}$ Kalol Institute of Pharmacy, Kalol 382 721, India \\ ${ }^{2}$ PES College of Pharmacy, Bangalore 560 085, India \\ ${ }^{3}$ S. K. Patel College of Pharmaceutical Education and Research, Vidyanagar 384 012, India \\ ${ }^{4}$ C. U. Shah College of Pharmacy and Research, Surendranagar 363 030, India
}

MS received 10 October 2011; revised 9 April 2012

\begin{abstract}
In the present study, carboxymethylchitosan (CMCS) was prepared from chitosan, crosslinked with glutaraldehyde and evaluated in vitro as a potential carrier for site specific drug delivery of lercanidipine hydrochloride (LERH). LERH was incorporated at the time of crosslinking of CMCS. The chitosan was evaluated for its degree of deacetylation $(D D)$ and average molecular weight, which were found to be $84.6 \%$ and $3.5 \times 10^{4} \mathrm{Da}$, respectively. The degree of substitution on prepared CMCS was found to be $\mathbf{0 . 6 8}$. All hydrogel formulations showed more than $86 \%$ and $77 \%$ yield and drug loading, respectively. The swelling behaviour of prepared hydrogels were checked in different $\mathrm{pH}$ values, $\mathbf{1 . 2 , 6 . 8}$ and 7.4 , indicated $\mathrm{pH}$ responsive swelling characteristic with very less swelling at pH 1.2 and quick swelling at $\mathrm{pH} 6.8$ followed by linear swelling at $\mathrm{pH} 7.4$ with slight increase. In vitro release profile was carried out at the same conditions as in swelling and drug release was found to be dependent on swelling of hydrogels and showed biphasic release pattern with non-fickian diffusion kinetics at higher $\mathrm{pH}$. The carboxymethylation of chitosan, entrapment of drug and its interaction in prepared hydrogels were checked by FTIR, ${ }^{1} \mathrm{H}-\mathrm{NMR}$, DSC and $p$-XRD studies, which confirmed formation of CMCS from chitosan and absence of any significant chemical change in LERH after being entrapped in crosslinked hydrogel formulations. The surface morphology of formulation $S 6$ was checked before and after dissolution, revealed open channel like pores formation after dissolution.
\end{abstract}

Keywords. Chitosan; carboxymethyl chitosan; hydrogel; site specific; lercanidipine hydrochloride.

\section{Introduction}

Controlled drug delivery technology using natural biodegradable polymers as carriers represents one of the most rapidly advancing areas of science. Chitin and its derivatives have been widely utilized as excipients in pharmaceutics to purposefully delivery drugs or nutriments (Wang et al 2008).

Carboxymethylchitosan (CMCS) is an attractive biocompatible and biodegradable polymer which is obtained from the reaction of chitosan with monochloroacetic acid and in alkaline condition (Chen S et al 2004). Due to its antimicrobial activity, film-forming ability and capacity to interact with different substances and solubility in wide range of $\mathrm{pH}$, it is used in medical and pharmaceutical areas, mainly for the controlled release of drug (Raimunda-de-Abreu and Campana-Filho 2009). It is also used in tissue engineering and viscosupplementation (Chen $\mathrm{S}$ et al 2004).

Comparing with commonly used chitosan, CMCS shows several potentials in local drug delivery (Wang et al 2008). Local application of drug delivery system could be very

\footnotetext{
*Author for correspondence (subhashvaghani@gmail.com)
}

advantageous, both in terms of raising drug concentration directly in the action site, and in preventing systemic side effects such as gastrointestinal complaints, depression and tachycardia (Wang et al 2008).

Examples of the advantages of site-specific employing CMCS vehicles include $\mathrm{pH}$-sensitivity, bioadhesive ability, solubility and absorbability, controllable biodegradability, nontoxicity of the degradation end products, sustained release potential and ease of administration (Chen S et al 2004; Yinsong et al 2007). The swelling, drug permeation and release properties of CMCS can be controlled by the $\mathrm{pH}$ changes because it contains cationic amine groups and anionic carboxyl groups in matrix (Chen $\mathrm{S}$ et al 2004).

Hypertension is one of the major risk factors for coronary artery disease and the most important risk factor for cerebrovascular diseases (Jabor et al 2003). Antihypertensive drugs diminish cardiovascular risk in hypertensive patients by lowering blood pressure (Jabor et al 2003).

Upon oral administration of an immediate release form of LERH, peak plasma level occurs $1-3 \mathrm{~h}$ following administration and falls below $1 \mathrm{ng} / \mathrm{ml}$ by $24 \mathrm{~h}$. As the modified release dosage forms can be used to prolong pharmacologic action and reduce variability in the plasma concentration of a drug, 
LERH encapsulated CMCS hydrogels are developed to provide the modified release of LERH such that it can provide $\mathrm{pH}$ dependant drug release in sustained manner for $24 \mathrm{~h}$.

The objective of the present study was to prepare CMCS from chitosan and use it as carrier for $\mathrm{pH}$ specific controlled drug delivery for lercanidipine hydrochloride (LERH), hence its erratic absorption could be reduced with increased oral bioavailability. In this study, chitosan was modified by carboxymethylation and the characteristics of CMCS were studied, and it was used as the controlled release carrier for LERH for $\mathrm{pH}$ specific drug delivery.

\section{Materials and methods}

\subsection{Materials}

Chitosan was a kind gift from Central Marine Fisheries Research Institute, Cochin. LERH was obtained as a gift sample from Zydus Research Centre, Ahmedabad. Monochloroacetic acid, isopropyl alcohol and methanol were purchased from Rankem (India). All other chemicals and reagents used were of analytical grades and used as received.

\subsection{Methods}

2.2a Characterization of chitosan: The average molecular weight of chitosan was determined using the MarkHouwink visometry method in a solvent of $0.1 \mathrm{M}$ acetic acid/0.2 $\mathrm{M} \mathrm{NaCl}$ maintained at $25^{\circ} \mathrm{C}$ (El-Sherbiny 2010). The degree of $N$-deacetylation was determined by FTIR using the following relationship:

$$
\% N \text {-deacetylation }=100\left[1-\left(\frac{A_{1676}}{A_{3400}}\right)\left(\frac{1}{1 \cdot 33}\right)\right],
$$

where $A$ is the absorbance at the given wave number. These two absorption signals at about 1676 and $3400 \mathrm{~cm}^{-1}$ correspond to the amide and the primary amino groups of chitosan. The factor (1.33) represents the value of ratio $A_{1676} / A_{3400}$ for the fully $N$-acetylated chitosan (El-Sherbiny 2009).

2.2b Preparation of Carboxymethylchitosan (CMCS): CMCS was synthesized as per the method described earlier with slight modification. In brief, $2 \mathrm{~g}$ of chitosan was added to $50 \mathrm{ml}$ isopropyl alcohol and stirred using magnetic stirrer at room temperature for $2 \mathrm{~h}$. The suspension was then transferred to $500 \mathrm{ml} \mathrm{RBF}$ and $80 \mathrm{ml}$ of aqueous $\mathrm{NaOH}$ solution $(60 \%)$ was added and refluxed at $85^{\circ} \mathrm{C}$ for $4 \mathrm{~h}$. Then, $100 \mathrm{ml}$ of aqueous monochloroacetic acid solution $(60 \% \mathrm{w} / \mathrm{v})$ was added in 5 equal parts over a period of $10 \mathrm{~min}$. The mixture was heated with stirring, at $65^{\circ} \mathrm{C}$ for further $8 \mathrm{~h}$. The reaction mixture was then neutralized using $\mathrm{HCl}$ solution (4 M). After removal of the undissolved residue by filtration, the resulting CMCS were precipitated by adding methanol. The product was filtered, washed several times with a mixture of $\mathrm{CH}_{3} \mathrm{OH} /$ $\mathrm{H}_{2} \mathrm{O}(1: 1)$ and dried under vacuum (El-Sherbiny 2010).

2.2c Degree of substitution: Degree of substitution $\left(D_{\mathrm{s}}\right)$ which is the relative number of carboxymethylated groups in the chitosan chain was determined using conductimetric method (Zamani et al 2010). A solution of $0 \cdot 1 \mathrm{~g}$ of CMCS in $100 \mathrm{ml}$ of $0.05 \mathrm{M} \mathrm{HCl}$ was prepared and the $\mathrm{pH}$ was increased to $2 \cdot 0$ by adding $0 \cdot 1 \mathrm{M} \mathrm{NaOH}$ solution. It was then titrated with $0 \cdot 1 \mathrm{M} \mathrm{NaOH}$ up to $\mathrm{pH} 11 \cdot 5$. The titration curve is shown in figure 1 , and $D_{\mathrm{s}}$ value was calculated as follows

$$
D_{\mathrm{s}}=\frac{\left(\mathrm{V}_{2}-\mathrm{V}_{1}\right) \times D D}{\mathrm{~V}_{3}-\mathrm{V}_{2}},
$$

where $D_{\mathrm{s}}$ is the degree of substitution of prepared CMCS and $D D$ the degree of deacetylation of chitosan (Zamani et al 2010).

2.2d HPLC analysis: HPLC measurements were carried out by using a Shimadzu LC 2010 AHT system equipped with a wavelength detector at $356 \mathrm{~nm}$ and a Kromasil $\mathrm{C}_{18}(250 \times 4.6 \mathrm{~mm}$ ID, $5 \mu \mathrm{m}$ pore size $)$ column with auto integrator. The mobile phase consisted of acetonitrile/0.01 M phosphate buffer, $\mathrm{pH} 4.0$ in $65: 35 \mathrm{v} / \mathrm{v}$ ratio. The flow rate was kept as $1.0 \mathrm{ml} / \mathrm{min}$ at $50^{\circ} \mathrm{C}$ for $15 \mathrm{~min}$ run time with a pressure of 1500 PSI. The retention time of LERH was $5 \cdot 1 \mathrm{~min}$. The calibration curve at concentrations varying from $1 \mu \mathrm{g} / \mathrm{ml}$ to $20 \mu \mathrm{g} / \mathrm{ml}$ was used to evaluate all the samples with $20 \mu \mathrm{l}$ injection volume. The details of linearity and validation are mentioned in table 1 .

2.2e Formulation of hydrogel, yield and drug entrapment: For the synthesis of hydrogel, 3\% CMCS (w/w) was filtered, degassed and transferred to a cylindrical mould in which different amounts of LERH was added according to the ratios with CMCS as shown in table 2. Glutaraldehyde $(2.5 \% \mathrm{v} / \mathrm{v})$ was added as a crosslinking agent to the above

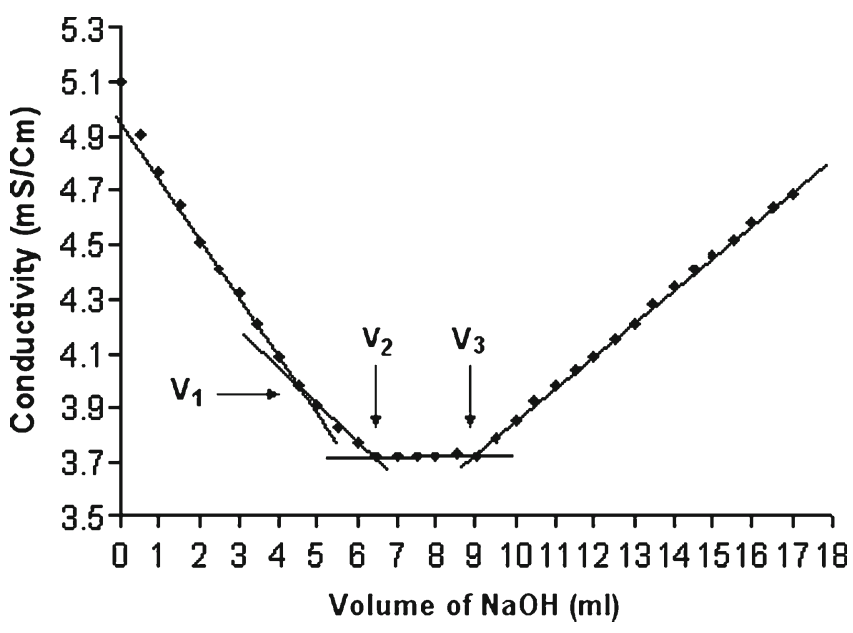

Figure 1. Cunductimetric titration curve of $\mathrm{CMCs}$ in $\mathrm{HCl}$ titrated with $\mathrm{NaOH}$ solution. 
suspension and kept at room temperature overnight for gel formation (Chen S et al 2004). The crosslinked hydrogels were removed and washed several times with distilled water to remove un-reacted glutaraldeyde and dried under vacuum until used.

The yield of prepared formulations were calculated as per the following equation

$$
\% \text { Yield }=(A / B) \times 100,
$$

where $A$ is the actual weight of hydrogel and B the theoretical weight of hydrogel.

The entrapment efficiency of LERH in hydrogel was calculated using the following equation

$$
\begin{aligned}
& \% \text { Entrapment efficiency } \\
& =\frac{(\text { Actual amount of drug in hydrogen }) \times 100}{\text { Theoretical amount of drug in hydrogel }} .
\end{aligned}
$$

To calculate entrapment efficiency, the amount of dried hydrogels equivalent to $20 \mathrm{mg}$ of LERH was taken. These hydrogels were stirred at $100 \mathrm{rpm}$ for $48 \mathrm{~h}$ in phosphate buffer solution (PBS, pH 6.8), diluted further and analysed at 356 nm using HPLC (Shimadzu LC 2010 AHT, Japan).

2.2f Swelling studies: Swelling of the hydrogels was determined by placing hydrogel in $100 \mathrm{ml}$ solutions with $\mathrm{pH}$ values of $1.2,6.8$ and 7.4 maintained at $37 \pm 0.5^{\circ} \mathrm{C}$ for $2 \mathrm{~h}$, $3 \mathrm{~h}$ and $19 \mathrm{~h}$, respectively (Tavakol et al 2009). The hydrogels were collected at regular intervals of time; the excess of moisture was blotted off and weighed. The weight change of wet hydrogels and dry hydrogels were noted using the following expression (Vaghani et al 2010a):

$\%$ Swelling index $=\left[\left(W_{\mathrm{t}}-W_{0}\right) / W_{0}\right] \times 100$,

Table 1. Summary of calibration curve and validation of HPLC method used for LERH

\begin{tabular}{ll}
\hline Linearity range (ppm) & $0 \cdot 5-20$ \\
$R^{2}$ & 0.9999 \\
Slope & 13615 \\
Intercept & -266 \\
LOD (ppm) & 0.07 \\
LOQ (ppm) & 0.22 \\
\hline
\end{tabular}

where $W_{\mathrm{t}}$ and $W_{0}$ are the weight of the hydrogels at time ' $\mathrm{t}$ ' and dry state, respectively.

$2.2 \mathrm{~g}$ In vitro drug release studies: The in vitro dissolution study of LERH from hydrogels was performed using USP XXIV dissolution rate test apparatus (type II, model TDT08L, Electrolab, Mumbai, India) fitted with paddle (100 rpm) at $37 \pm 0 \cdot 5^{\circ} \mathrm{C}$ using $250 \mathrm{ml}$ simulated gastric fluid (SGF, pH 1.2) for $2 \mathrm{~h}, 900 \mathrm{ml}$ phosphate buffer solution (PBS, $\mathrm{pH} 6.8$ ) for next $3 \mathrm{~h}$ and subsequently in $900 \mathrm{ml} \mathrm{PBS}(\mathrm{pH}$ 7.4) for $12 \mathrm{~h}$. Weight equivalent to $20 \mathrm{mg}$ of LERH was taken for dissolution. At the predetermined time interval, $10 \mathrm{ml}$ samples were withdrawn, filtered through a $0.45 \mu \mathrm{m}$ membrane filter, diluted and assayed as per the above mentioned method. Cumulative percentage drug release was calculated using an equation obtained from a calibration curve.

2.2h Release kinetics: Data obtained from in vitro release studies were fitted to various kinetics equations to discover the mechanism of drug release from prepared formulations. The kinetic models used were of zero order, first order, Higuchi and Korsemeyer-Peppas models. The rate constants were also calculated for the respective models (Vaghani et al 2010a).

Korsmeyer-Peppas model, describing drug release from polymeric system, takes into account that the drug release mechanism often deviates from the Fick's law and follows anomalous behaviour described by the following equation:

$$
M_{\mathrm{t}} / M_{\infty}=k t^{n}
$$

where $M_{\mathrm{t}}$ is the drug released at time t, $M_{\infty}$ the quantity of drug released at infinite time, $k$ the kinetic constant and $n$ the release exponent. The value of $n$ is related to the geometrical shape of the delivery systems and determines the release mechanism.

The release data was further treated according to Higuchi equation

$$
Q=k t^{1 / 2},
$$

where $Q$ is the percent of drug released at time, $t$ and $k$ the kinetic constant.

The value of $n$ in (6) determines the mechanism of drug release. When $n$ approximates to $0 \cdot 5$, a Fickian/diffusion

Table 2. Formulae for hydrogel preparation, yield and entrapment efficiency of various hydrogel formulations.

\begin{tabular}{lccc}
\hline & & & $\begin{array}{c}\% \text { Entrapment } \\
\text { efficiency } \\
(n=3 \pm \text { SD })\end{array}$ \\
\hline Formulation & Drug:CMCs & Yield $(n=3 \pm$ SD $)$ & $81 \cdot 54 \pm 4 \cdot 27$ \\
S2 & $1: 0 \cdot 25$ & $86 \cdot 32 \pm 3 \cdot 01$ & $78 \cdot 73 \pm 3 \cdot 83$ \\
S3 & $1: 0.5$ & $87.69 \pm 2 \cdot 12$ & $77.61 \pm 2.97$ \\
$S 4$ & $1: 1$ & $91 \cdot 34 \pm 4 \cdot 19$ & $82 \cdot 32 \pm 2 \cdot 34$ \\
$S 5$ & $1: 1.5$ & $92 \cdot 51 \pm 3 \cdot 07$ & $85.73 \pm 3 \cdot 09$ \\
$S 6$ & $1: 2$ & $93 \cdot 16 \pm 2 \cdot 78$ & $86.95 \pm 3 \cdot 12$ \\
\hline
\end{tabular}


controlled release is implied, where $0.5<n<1.0$ nonFickian transport and for $n=1$, zero order (case II transport). When $n$ approaches 1.0 , phenomenologically one may conclude that the release is approaching zero order (Vaghani et al 2010a).

2.2i FTIR study: The formation of CMCS and drugpolymer interactions were studied by FTIR spectroscopy. IR spectra for chitosan, CMCS, LERH and formulation $S 6$ were recorded in a Fourier transform infrared (FTIR) spectrophotometer (FTIR-8400 S, Shimadzu, Japan) with $\mathrm{KBr}$ pellets. The scanning range was $400-4000 \mathrm{~cm}^{-1}$ (Vaghani et al 2010b).

$2.2 \mathrm{j}$ Nuclear magnetic resonance (NMR) study: NMR study was carried out to confirm the formation of CMCS. The ${ }^{1} \mathrm{H}$ FT-NMR spectrum of CMCS was acquired at room temperature, using $500 \mathrm{MHz}$ spectrometer (Bruker AVANCE). The polymer solution in $\mathrm{D}_{2} \mathrm{O}$ was prepared for acquiring the spectrum.

$2.2 \mathrm{k}$ Differential scanning calorimetry (DSC): DSC scans of about $10 \mathrm{mg}$, accurately weighed chitosan, CMCS, LERH and formulation $S 6$ were performed by using an automatic thermal analyser system (DSC 60, Shimadzu, Japan) with TDS tread line software. Sealed aluminum-lead pans were used in the experiments for all the samples. All the samples were run at a scanning rate of $10{ }^{\circ} \mathrm{C} / \mathrm{min}$ from 50-300 ${ }^{\circ} \mathrm{C}$ (Vaghani et al 2010b).

2.21 Powder X-ray diffractometry (PXRD): The powder $X$-ray diffraction study was carried out to characterize the polymorphic forms of chitosan, CMCS, LERH and formulation S6. A Philips X'Pert PW 3040/60 (Almelo, the Netherlands) was used as an X-ray generator for $\mathrm{CuK} \alpha$ radiation $(\lambda=1.54178 \AA)$. Data was collected in a continuous scan mode using a step size of $0.01^{\circ} 2 \theta$. The scanned range was $5-50^{\circ}$ (Vaghani et al 2010b).

2.2m Scanning electron microscopy (SEM): SEM was used to examine the surface morphology of formulation $S 6$ before and after dissolution. Dried films were mounted onto stubs by using double-sided adhesive tape. The films were coated with gold and observed under a scanning electron microscope (JEOL, JSM-5600 LV, Japan) for surface characteristics (Vaghani et al 2010b).

\section{Results and discussion}

\subsection{Characterization of chitosan and preparation of CMCS}

The average molecular weight and $\% N$-deacetylation of chitosan were found to be $3.5 \times 10^{4} \mathrm{Da}$ and $84.6 \%$, respectively. For the carboxymethylation on chitosan, 2 sites are available, hydroxyl groups bonded to $\mathrm{C}_{3}$ and $\mathrm{C}_{6}$ of glucopyranose unit as well as the amino group bonded to $\mathrm{C}_{2}$. As per the literature (Le-Dung et al 1994; Chen et al 2002; Chen and Park 2003; Chen L et al 2004; Yinsong et al 2007; Raimundade-Abreu and Campana-Filho 2009), the carboxymethylation occurs at $\mathrm{C}_{2}$ and $\mathrm{C}_{6}$ when the reaction is carried out at elevated temperature and room temperature, respectively. In the present study, carboxymethylation was carried out by reaction of chitosan with monochloroacetic acid in isopropyl alcohol/aqueous sodium hydroxide at elevated temperature so carboxymethylation of chitosan would have occurred on amino group bonded to $\mathrm{C}_{2}$. As shown in figure 1, four linear branches were observed in conductimetric titration curve of CMCS. The first branch was attributed to the volume of $\mathrm{NaOH}$ used for neutralization of the excess amount of $\mathrm{HCl}$ ( 0 to $\mathrm{V}_{1}$ ). The second branch showed that the $\mathrm{NaOH}$ volume reacted with carboxymethyl groups $\left(\mathrm{V}_{1}\right.$ to $\left.\mathrm{V}_{2}\right)$. The third branch showed that the volume of $\mathrm{NaOH}$ reacted with $\mathrm{NH}_{3}^{+}$ groups. The fourth branch resulted due to the excess amount of $\mathrm{NaOH}$ in the solution. Here $\mathrm{V}_{3}-\mathrm{V}_{2}$ is not dependent on the number of carboxymethylated groups and is proportional to the number of glucosamine residues on chitosan chain, hence, $\left(\mathrm{V}_{3}-\mathrm{V}_{2}\right) / D D$ is proportional to the number of building blocks of the polymer chains (Zamani et al 2010). So $D_{\text {s }}$ can be calculated as per (1), and found to be 0.68 for the prepared CMCS.

\subsection{Yield of preparation and entrapment of drug}

As shown in table 2, all the formulations showed more than $86.32 \%$ and $77.61 \%$ yield and drug loading, respectively. The high yield of the preparation was attributed because no loss step was involved while preparation except washing. Some amount of drug was lost during washing of hydrogels.

High $D_{\mathrm{s}}$ resulted in stronger intermolecular interaction which resulted in higher entrapment of LERH in the formulations. With decreasing $D_{\mathrm{s}}$ value, the isoelectric point (IEP) of CMCS shifted to higher $\mathrm{pH}$ value and the minimum degree of swelling value at IEP increased due to less intraionic attractions between opposite charges with decreasing amount of $\mathrm{COO}^{-}$groups. When $\mathrm{pH}$ increased, CMCS gels was due to increase in intermolecular hydrogen bonding with increasing amount of carboxymethyl groups, which counteract the osmotic pressure and clasp the gel (Chen S et al 2004).

\subsection{Swelling studies}

The prepared formulations were checked for their swelling in simulated gastric fluid (SGF, $\mathrm{pH} 1.2$ ) for $2 \mathrm{~h}$, in phosphate buffer solution (PBS, pH 6.8) for $3 \mathrm{~h}$ and successively in PBS (pH 7.4) for $7 \mathrm{~h}$ (18). Figure 2 shows \% SI profiles of various formulations. Results indicated that at $\mathrm{pH} 1.2$ for $2 \mathrm{~h}$, all the formulations showed less than $10.32 \%$ swelling while at $\mathrm{pH} 6.8$ for next $3 \mathrm{~h}$ showed high swelling up to $100.07 \%$. The swelling was further increased slightly at $\mathrm{pH}$ 7.4 and observed at about $135.22 \%$. The swelling ratio was 


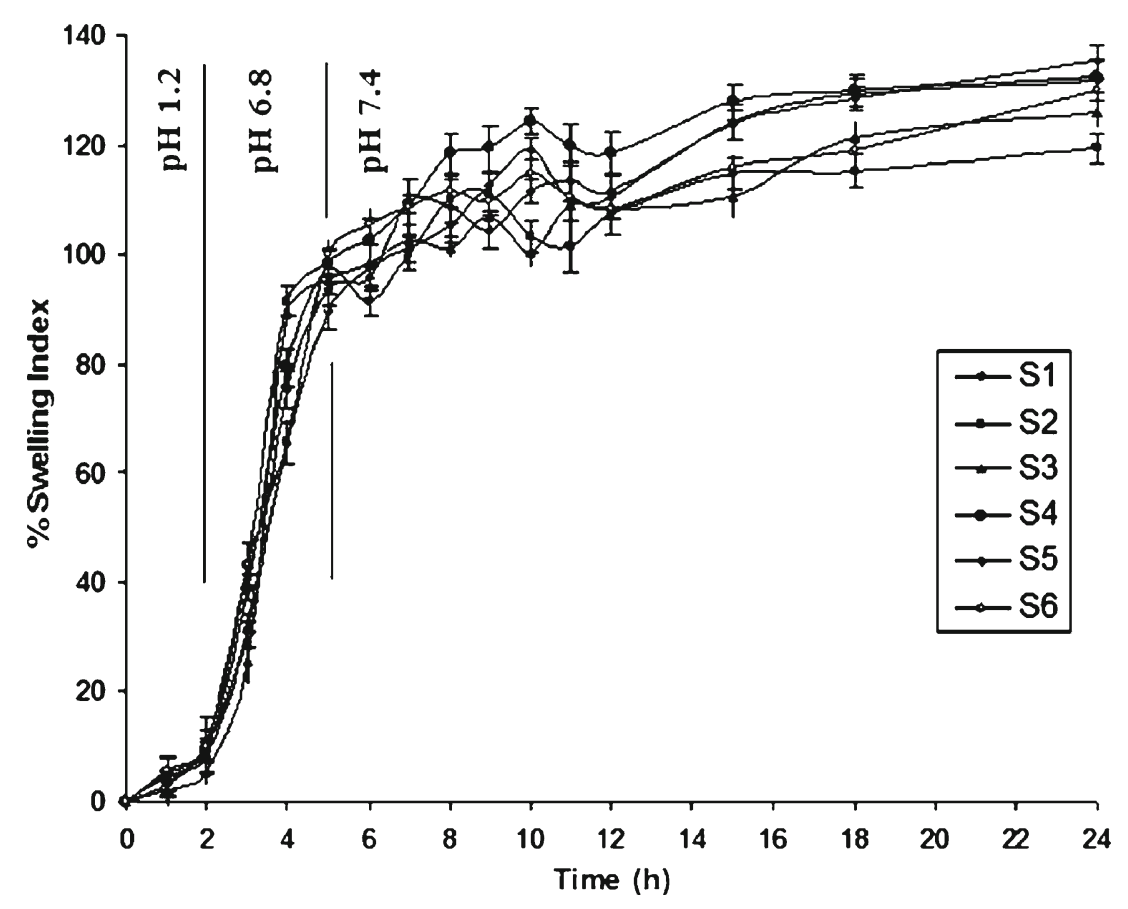

Figure 2. Swelling behaviour of formulations $S 1-S 6$ in different $\mathrm{pH}$ conditions.

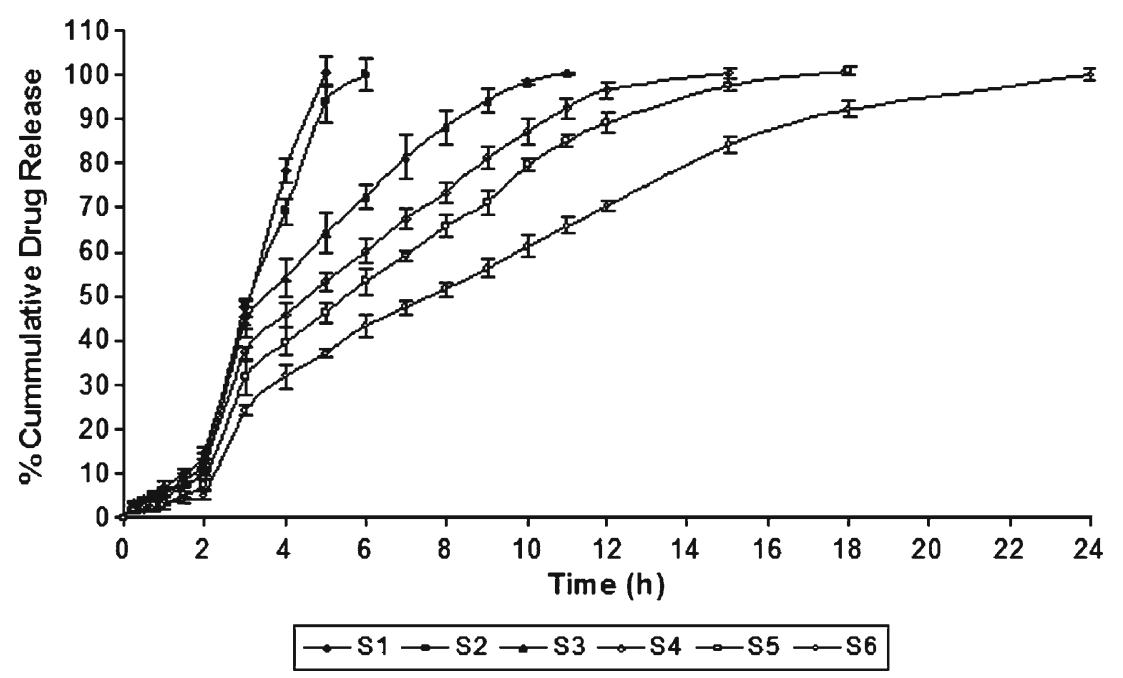

Figure 3. Release profiles of LERH from hydrogel formulations $S 1-S 6$.

varied as the amount of CMCS was varied in various formulations because the swelling was attributed to its amount. The state of the swelling mainly depends on osmotic pressure difference between inside the gel and the surroundings caused by the redistribution of mobile ions (Chen S et al 2004). Here $\mathrm{pH}$ dependant swelling was observed because prepared CMCS hydrogels contain both carboxyl and amino groups, and thus forms a network with oppositely charged structures which could change the charge state of the ionic groups varying with $\mathrm{pH}$. Further, it also depends on the degree of deacetylation $(D D)$ and degree of substitution $\left(D_{\mathrm{s}}\right)$ of prepared CMCS (Chen S et al 2004). At pH 1.2, the dom- inant charges in the gels are protonated amino groups. As the $D D$ of the obtained chitosan was found to be $84.6 \%$ and $D_{\mathrm{s}}$ of prepared CMCS was observed as 0.68 , as per ${ }^{1} \mathrm{H}$ NMR study only about $27 \%$ amino groups were available on CMCS. Due to the fewer amounts of amino groups, and further crosslinked, which are responsible for swelling at low $\mathrm{pH}$, the swelling was found to be limited up to $10 \cdot 32 \%$. In case of higher $\mathrm{pH}(\mathrm{pH} 6.8$ and $\mathrm{pH} 7.4)$, the dominant charges in the gels are the unprotonated carboxyl groups. The swelling at these conditions was higher as compared to low $\mathrm{pH}(1 \cdot 2)$ due to about $58 \%$ unprotonated carboxyl ions. 


\subsection{In vitro drug release studies and release kinetics}

The release profile of LERH from various hydrogel formulations is shown in figure 3. Formulations $S 1$ and $S 2$ failed to retard the drug release and found to be disintegrate within $5 \mathrm{~h}$ and $6 \mathrm{~h}$, respectively. In these formulations very less amounts of CMCS were present as the ratio of drug:CMCS kept as 1:0.25 and 1:0.5 (table 2) so matrices of CMCS failed to provide adequate retention of drug. Formulations $S 3, S 4$ and $S 5$ also failed to retard the drug for $24 \mathrm{~h}$ and complete drug releases were observed within $11 \mathrm{~h}, 15 \mathrm{~h}$ and $18 \mathrm{~h}$, respectively. Though the amounts of CMCS were high in these formulations as compared to $S 1$ and $S 2$, then also it was not sufficient to retard the drug release in controlled manner for $24 \mathrm{~h}$. Formulation $S 6$ provided adequate drug retention and controlled release for $24 \mathrm{~h}$ with complete drug release at $24 \mathrm{~h}$, so this formulation was considered as an optimized formulation and further study was carried out using this formulation. The differences in drug releases were observed depending upon the swelling behaviour. Though the swelling was completely different, release was also affected by the drug loading in the polymer matrix of respected formulations and the concentration of polymers in the formulations (table 2) (Koutroumanis et al 2010). LERH showed biphasic $\mathrm{pH}$ dependent release pattern from all the formulations. The release was very less from all the formulations for first $2 \mathrm{~h}$, as the dissolution was carried out at $\mathrm{pH} 1 \cdot 2$. At $\mathrm{pH} 1 \cdot 2$, swelling of hydrogels were very less, as discussed in swelling studies, hence the drug was unable to diffuse from the hydrogels. Some amounts of drug release were observed due to swelling and the free drug remaining at the surfaces that was not entrapped efficiently within the crosslinked polymer network (Prabaharan and Gong 2008). Release rate was increased at higher $\mathrm{pH}$ as compared to release at $\mathrm{pH} 1.2$ due to the fact that the hydrogels swelled rapidly at $\mathrm{pH} 6.8$ and also the swelling was found to be almost linear with a slight increase at $\mathrm{pH} 7.4$. Drug release was found to be followed by first order kinetics for first $2 \mathrm{~h}$ and showed non-fickian diffusion (diffusion coupled with erosion) kinetics with $n>0.5$ value for further release at higher $\mathrm{pH}$ (table 3) (Vaghani et al 2010a).

\subsection{FTIR study}

As shown in figure 4, FTIR spectrum of chitosan showed a broad absorption band between $3500 \mathrm{~cm}^{-1}$ and $3100 \mathrm{~cm}^{-1}$, centred at $3400 \mathrm{~cm}^{-1}$, due to $\mathrm{O}-\mathrm{H}$ stretching vibration, $\mathrm{N}-\mathrm{H}$ extension vibration and the intermolecular $\mathrm{H}$-bonds of the polysaccharide moieties (figure 4a) (Raimunda-deAbreu and Campana-Filho 2009; El-Sherbiny 2009, 2010). A band at $2881 \mathrm{~cm}^{-1}$ was observed corresponding to the axial stretching of $\mathrm{C}-\mathrm{H}$-bonds. A peak at $1676 \mathrm{~cm}^{-1}$ was observed which is attributed to the axial stretching of $\mathrm{C}=\mathrm{O}$ bonds of the acetamide group which indicated that sample was not fully acetylated. A band at $1557 \mathrm{~cm}^{-1}$ was observed, which is attributed to the angular deformation of the $\mathrm{N}-\mathrm{H}$ bonds of the amino group. A band at $1370 \mathrm{~cm}^{-1}$ due to the symmetrical angular deformation of $\mathrm{CH}_{3}$ and the amide III band at $1320 \mathrm{~cm}^{-1}$ were observed. The band corresponding to the polysaccharide skeleton, including vibrations of the glycoside bonds, $\mathrm{C}-\mathrm{O}$ and $\mathrm{C}-\mathrm{O}-\mathrm{C}$ stretching in range $1156-898 \mathrm{~cm}^{-1}$, was observed.

The carboxymethylation provoked structural changes which were clearly identified by comparing the infrared spectra of chitosan and carboxymethylchitosan. The occurrence of a broader band centred at $3444 \mathrm{~cm}^{-1}$ revealed more hydrophilic character of CMCS as compared to the parent chitosan (figure 4b). The introduction of carboxymethyl groups was cofirmed by the occurrence of an intense band at $1593 \mathrm{~cm}^{-1}$ and a moderate band at $1423 \mathrm{~cm}^{-1}$. These bands were attributed to symmetric and asymmetric deformation of $\mathrm{COO}^{-}$, respectively (Zhao et al 2002; Chen et al 2007; Raimunda-de-Abreu and Campana-Filho 2009).

As shown in figure 4c, FTIR spectrum of LERH exhibited peaks at $3184.25 \mathrm{~cm}^{-1}$ due to $\mathrm{NH}$ stretching, at $3064.68 \mathrm{~cm}^{-1}$ and $2948.96 \mathrm{~cm}^{-1}$ attributed to alkyl and phenyl stretching, respectively; $2655.68 \mathrm{~cm}^{-1}$ due to

Table 3. Correlation coefficients of different pharmacokinetic models for LERH release profile from $S 1-S 6$.

\begin{tabular}{|c|c|c|c|c|c|c|c|}
\hline \multirow[b]{2}{*}{ Sl. No. } & \multirow[b]{2}{*}{ Time } & \multirow[b]{2}{*}{ Formulation } & \multirow{2}{*}{$\frac{\text { Zero order }}{R^{2}}$} & \multirow{2}{*}{$\frac{\text { First order }}{R^{2}}$} & \multirow{2}{*}{$\frac{\text { Higuchi }}{R^{2}}$} & \multicolumn{2}{|c|}{ Korsemeyer-Peppas } \\
\hline & & & & & & $N$ & $R^{2}$ \\
\hline 1 & Up to 2 & $S 1$ & 0.9878 & 0.9566 & 0.9945 & 1.5578 & $0 \cdot 9813$ \\
\hline 2 & & $S 2$ & 0.9542 & 0.9269 & 0.9692 & $1 \cdot 1214$ & $0 \cdot 9681$ \\
\hline 3 & & $S 3$ & 0.9694 & 0.9266 & 0.9907 & 0.6511 & 0.9905 \\
\hline 4 & & $S 4$ & $0 \cdot 9501$ & 0.8975 & 0.9818 & 0.6568 & 0.9879 \\
\hline 5 & & $S 5$ & 0.938 & $0 \cdot 8636$ & 0.9792 & 0.6872 & 0.984 \\
\hline 6 & & $S 6$ & $0 \cdot 9514$ & $0 \cdot 8508$ & 0.9888 & 0.6996 & 0.9902 \\
\hline 7 & $2-12$ & $S 1$ & 0.9878 & 0.9566 & 0.9945 & 1.5578 & $0 \cdot 9813$ \\
\hline 8 & & $S 2$ & 0.9542 & 0.9269 & 0.9692 & $1 \cdot 1214$ & $0 \cdot 9681$ \\
\hline 9 & & $S 3$ & 0.9694 & 0.9266 & 0.9907 & 0.6511 & 0.9905 \\
\hline 10 & & $S 4$ & 0.9501 & 0.8975 & 0.9818 & 0.6568 & 0.9879 \\
\hline 11 & & $S 5$ & 0.938 & 0.8636 & 0.9792 & 0.6872 & $0 \cdot 984$ \\
\hline 12 & & $S 6$ & $0 \cdot 9514$ & $0 \cdot 8508$ & 0.9888 & 0.6996 & $0 \cdot 9902$ \\
\hline
\end{tabular}




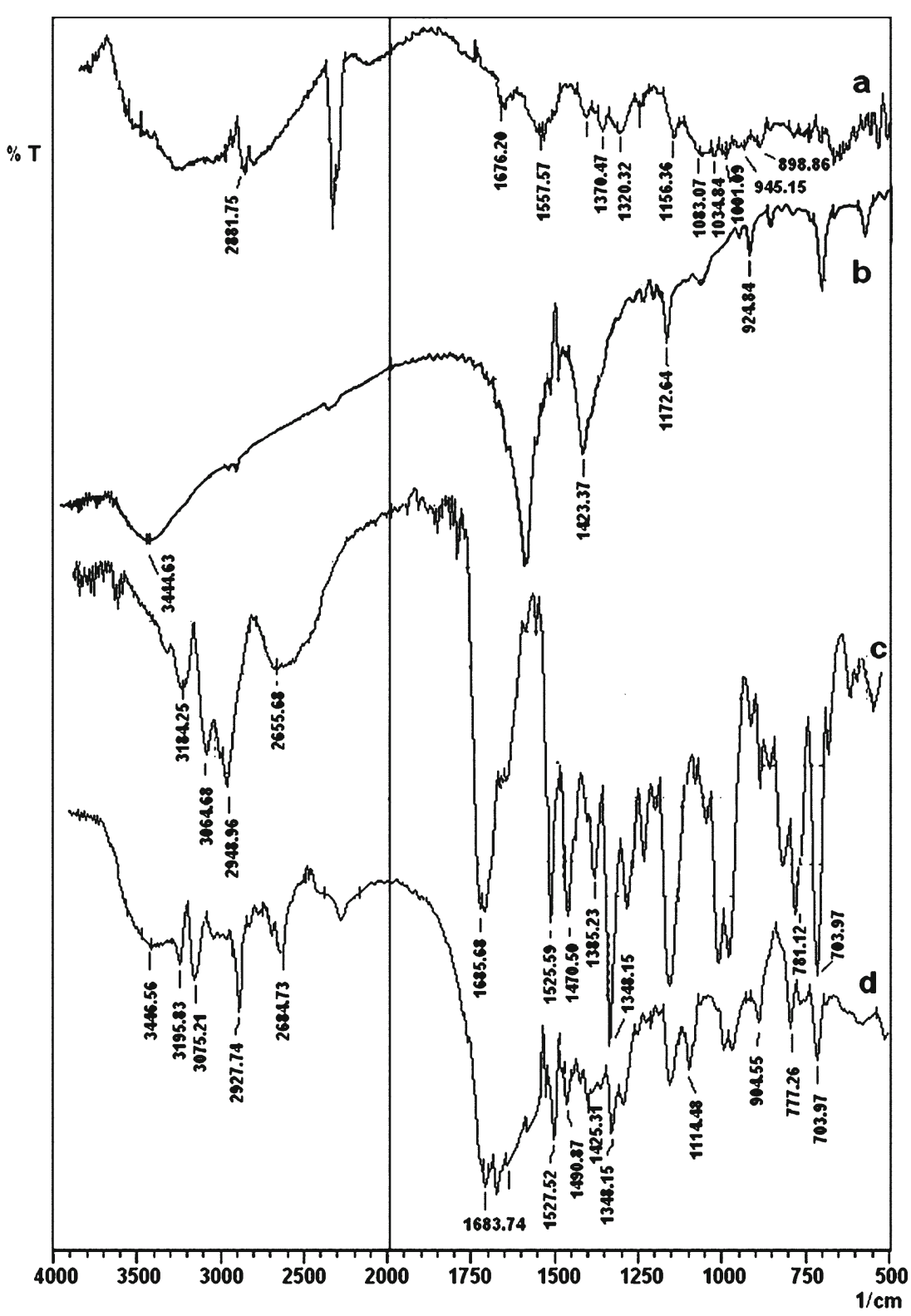

Figure 4. FTIR spectra of chitosan (a), prepared CMCs (b), LERH (c) and formulation $S 6(\mathbf{d})$.

$\mathrm{N}^{+}$stretching, $1685.68 \mathrm{~cm}^{-1}$ due to $\mathrm{C}=\mathrm{O}$ stretching, $1525.59 \mathrm{~cm}^{-1}$ and $1385.23 \mathrm{~cm}^{-1}$ due to symmetric and asymmetric stretching of $\mathrm{NO}_{2}$ group; $1470.5 \mathrm{~cm}^{-1}$ and $1385.23 \mathrm{~cm}^{-1}$ due to bending of geminal methyl group and at $781.12 \mathrm{~cm}^{-1}$ and $703.97 \mathrm{~cm}^{-1}$ due to out of plane bending of 5 and 3 adjacent hydrogen of aromatic ring (Charde et al 2008). All the peaks were maintained in formulation $S 6$ also (figure 4d) which confirmed presence of the drug in the formulation without any significant reaction of functional group with other ingredients.

\subsection{Nuclear magnetic resonance (NMR) study}

According to the literature, when carboxymethylation is carried out by reacting chitosan with mono-chloroacetic acid in iso-propanol and aqueous sodium hydroxide, $O$-substitution is favoured if the reaction is carried out at room temperature but $N$-substitution predominates by raising the reaction temperature (Tokura et al 1983; Le-Dung et al 1994; Chen and Park 2003; Chen et al 2002, 2004; Yinsong et al 2007; Prabaharan and Gong 2008; Raimunda-de-Abreu and Campana-Filho 2009). Figure 5 shows ${ }^{1} \mathrm{H}-\mathrm{NMR}$ spectrum of prepared CMCS. In the ${ }^{1} \mathrm{H}-\mathrm{NMR}$ spectrum of CMCS, signal at $3.2 \mathrm{ppm}$ was observed, the evidence of $N$ carboxymethylation at $C_{2}$. The appearance of small proton signal at $3.9 \mathrm{ppm}$ was due to occurrence of mono-substitution on some of the primary hydroxyl sites at $C_{6}$ of the modified chitosan structure, which indicated that less than $14 \%$ hydroxyl groups were also carboxymethylated during occurance of $N$-carboxymethylation. Though in the present study, 

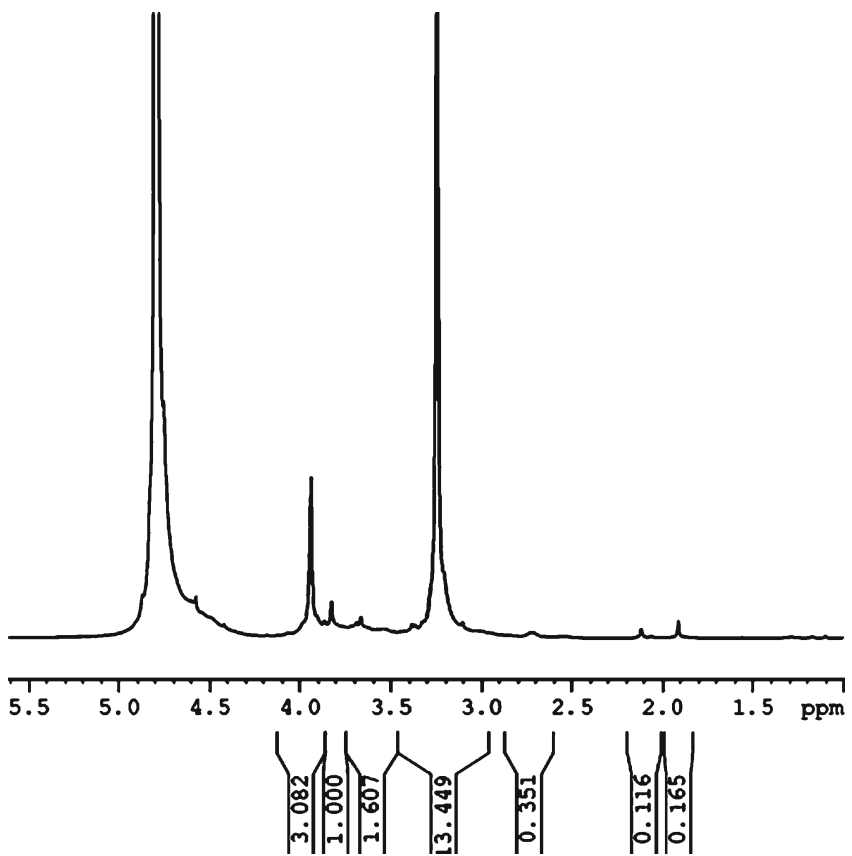

Figure 5. $\quad{ }^{1} \mathrm{H}$ NMR spectrum of prepared CMCs.

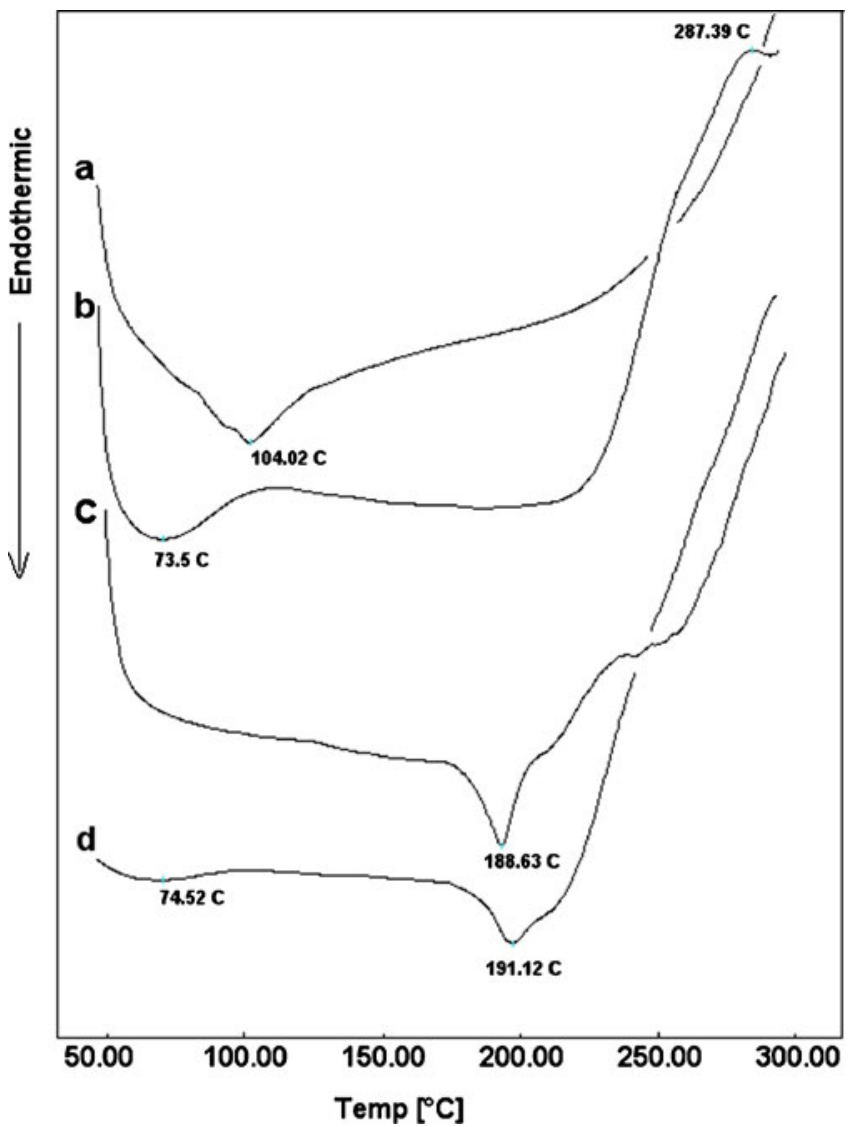

Figure 6. DSC thermograms of chitosan (a), CMCs (b), LERH (c) and formulation $S 6(\mathbf{d})$. reaction was carried out at elevated temperature of $<14 \%$ $O$-carboxymethylation also occurred. The signal assigned at $4.8 \mathrm{ppm}$ was due to the glucopyranose residue (Prabaharan and Gong 2008).

\subsection{DSC study}

DSC analysis was used to characterize thermal behaviour of chitosan and carboxymethylchitosan; as well as thermal behaviour of LERH in the prepared hydrogel formulation. In the present investigation, DSC thermograms of chitosan, CMCS, LERH and formulation S6 were taken (figure 6). The thermogram of pure chitosan showed a broad melting endotherm at $104.02^{\circ} \mathrm{C}$ (figure 6a) and thermogram of prepared CMCS showed a broad melting endotherm at $73.51^{\circ} \mathrm{C}$ (figure 6b). This transition may be due to loss of bound water. The decomposition of CMCS would have resulted in exothermic transition at around $287.39^{\circ} \mathrm{C}$ (figure $6 \mathrm{~b}$ ). The change in the pattern of thermal transition in the CMCS compared to chitosan confirms the carboxymethylation of

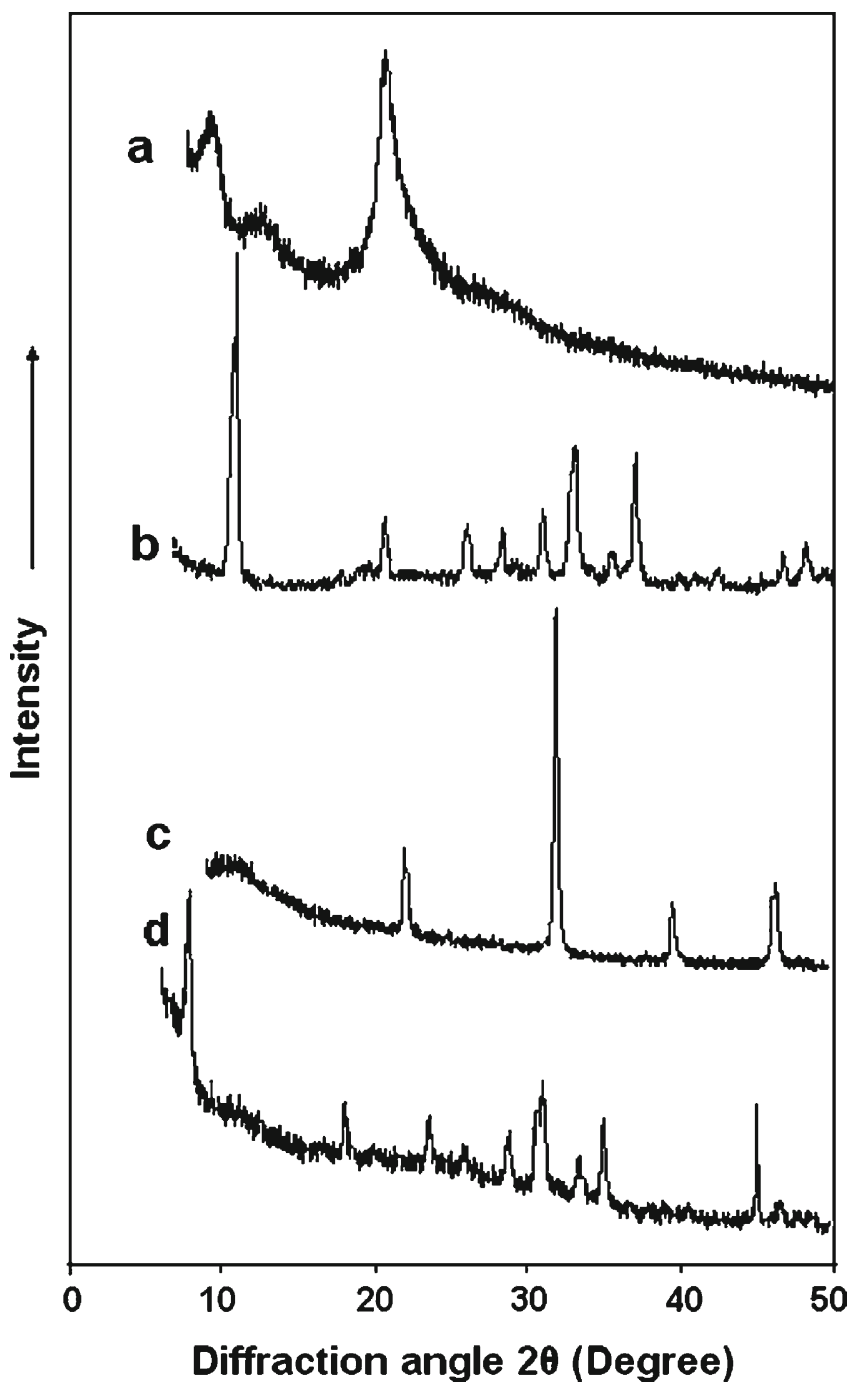

Figure 7. XRD pattern of pure chitosan (a), CMCs (b), LERH (c) and formulation $S 6(\mathbf{d})$. 

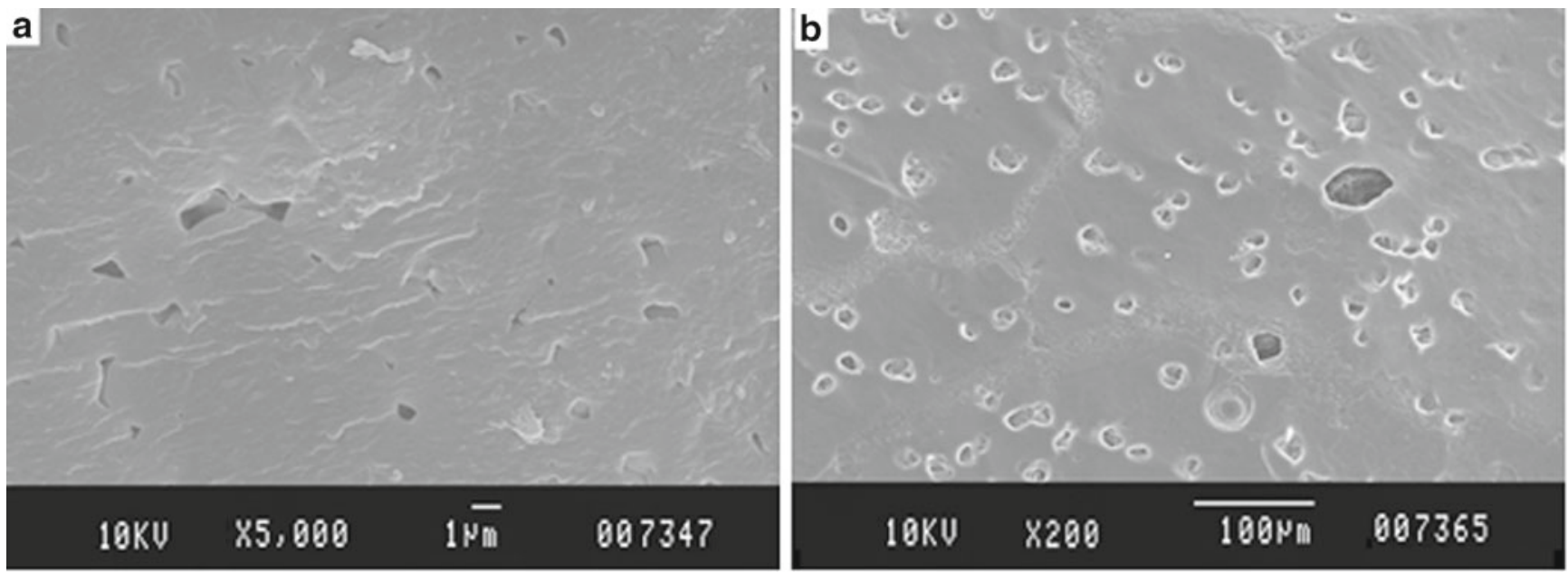

Figure 8. Scanning electron microscopy of formulation $S 6$ before dissolution (a) and after dissolution (b).

chitosan (El-Sherbiny 2009). Pure LERH showed sharp melting endotherm at $188.63^{\circ} \mathrm{C}$ (figure 6c) which corresponds to its melting point (Charde et al 2008). Drug may have been dispersed in the crystalline or amorphous form or dissolved in the polymer matrix during formation of hydrogel (Vaghani and Patel 2011). There is no detectable endotherm if the drug is present in a molecular dispersion or solid solution state in the polymeric matrix but in the formulation $S 6$ a sharp peak at $191.12^{\circ} \mathrm{C}$ as shown in figure $6 \mathrm{~d}$ was observed which indicated that the drug was not dispersed nor in the solid solution form in hydrogel. The study also revealed that the thermal behaviour and physical state of drug was not changed after being incorporated in formulation and also confirmed the presence of drug in the formulation.

\subsection{PXRD analysis}

Figure 7a shows XRD patterns of the chitosan. It can be seen that the strongest diffraction intensity is the broad peak around $2 \theta=17-23^{\circ}$ due to substrate chitosan. It indicated semicrystalline nature of chitosan (Pandit and Patil 2009). Figure $7 \mathrm{~b}$ shows XRD patterns of CMCS which indicated some sharp peaks at $9.34^{\circ}, 19.1^{\circ}, 26.9^{\circ}, 29.66^{\circ}, 31.68^{\circ}$, $34.22^{\circ}$ and $35.77^{\circ}$ which revealed the crystalline nature of prepared CMCS. It indicates that the carboxymethylation of chitosan resulted into crystalline form (El-Sherbiny 2009, 2010). In the spectra of LERH (figure 7c), strong characteristic peaks at $22.84^{\circ}, 32.52^{\circ}, 40 \cdot 1^{\circ}$ and $46 \cdot 68^{\circ}$ were observed, indicating its crystalline nature (Pandit and Patil 2009). Figure $7 \mathrm{~d}$ shows spectrum of formulation $S 6$, which indicated well maintained characteristic peaks of LERH, e.g., $24 \cdot 26^{\circ}$, $31.48^{\circ}, 33.9^{\circ}, 35.5^{\circ}$ and $45.4^{\circ}$ along with peaks of CMCS. The results indicated that during the formulation of hydrogels crystallinity of LERH was well maintained.

\subsection{Scanning electron microscopy (SEM)}

The surface morphology of prepared hydrogels was studied before and after dissolution. The surface morphology of formulation $S 6$ revealed non-porous translucent membrane (figure 8a) with some crystals of drug present on the surface. The surface morphology was again checked after dissolution which revealed open channel-like structure. Due to ionization of the carboxylic groups of CMCS at higher $\mathrm{pH}$, the chain relaxation occurs which leads to efficient solvent diffusion hence open channel-like structure (figure 8b) was generated in the hydrogel after dissolution.

\section{Conclusions}

In conclusion, the carboxymethylation of chitosan was successfully achieved and the occurrence of $N$-carboxymethylation was evidenced by FTIR and ${ }^{1} \mathrm{H}$ FT-NMR spectroscopy which revealed that $\mathrm{N}, \mathrm{O}$-carboxymethylchitosan was produced. The aforementioned results indicated the prepared CMCS hydrogels showed excellent $\mathrm{pH}$ sensitivity which indicated higher $\mathrm{pH}$ dependent swelling and drug release at pH 6.8 and 7.4. The prepared formulations were analysed by FTIR, DSC and pXRD showed absence of any significant chemical reaction of LERH in the formulation and found to be in crystalline form in final formulation also. SEM revealed channel like pore formation after dissolution. The results indicated the prepared hydrogels can be used as promising carriers for the administration of colon specific drug delivery of LERH.

\section{References}

Charde S, Mudgal M, Kumar L and Saha R 2008 AAPS Pharm. Sci. Technol. 9182

Chen J, Sun J, Yang L, Zhang Q, Zhu H, Wu H, Hoffmana A S and Kaetsu I 2007 Rad. Phys. Chem. 761425

Chen L, Du Y, Wu H and Xiao L 2002 J. Appl. Polym. Sci. 831233

Chen L, Tian Z and Du Y 2004 Biomaterials 253725

Chen S, Wu Y, Mi F, Lin Y, Yu L and Sung H 2004 J. Control Release 96285

Chen X G and Park H J 2003 Carbohydr. Polym. 8355 
El-Sherbiny I M 2009 Eur. Polym. J. 45199

El-Sherbiny I M 2010 Carbohydr. Polym. (in press)

Jabor V A P, Coelho E B, Ifa D B, Bonato P S, Santos N A G and Lanchote V L 2003 J. Chrom. B796 429

Koutroumanis K P, Avgoustakis K and Bikiaris D 2010 Carbohydr. Polym. 82181

Le-Dung P L, Milas M and Desbrieres J 1994 Carbohydr. Polym. 24209

Neira-Carrillo A, Yazdani-Pedram M, Retuert J, Diaz-Dosque M, Gallois S and Arias J L 2005 J. Colloid. Interf. Sci. 286134

Pandit S S and Patil A T 2009 J. Microencapsul. 26635

Prabaharan M, Gong S 2008 Carbohydr. Polym. 73117

Raimunda-de-Abreu F and Campana-Filho S P 2009 Carbohydr. Polym. 75214

Tavakol M, Vasheghani-Farahani E, Dolatabadi-Farahani T and Hashemi-Najafabadi S 2009 Carbohydr. Polym. 77326
Tokura S, Nishi N and Somorin T A 1983 Polym. J. 15 485

Vaghani S S, Patel S G, Jivani R J, Jivani N P, Patel M M and Borda R 2010a Pharm. Dev. Technol. 1-11, in Press

Vaghani S, Vasanti S, Chaturvedi K, Satish C S and Jivani N P 2010b Pharm. Dev. Technol. 15154

Vaghani S S and Patel M M 2011 Drug Dev. Ind. Pharm. 37 1160

Wang L C, Chen X G, Liu C S, Li D L, Ji Q X and Yu L J 2008 J. Appl. Polym. Sci. 1101136

Yinsong W, Lingrong L, Jian W and Zhang Q 2007 Carbohydr. Polym. 69597

Zamani A, Henriksson D and Taherzadeh M J 2010 Carbohydr. Polym. (in press)

Zhao Z, Wang Z, Ye N and Wang S 2002 Desalinisation 144 35 